\title{
UNA ACLARACIÓN NECESARIA
}

\author{
Marcos García de la Huerta
}

La intervención de Eduardo Carrasco en el Acto de Homenaje a Carla Cordua y Roberto Torretti contiene numerosas inexactitudes y equivocaciones. Me limitaré a comentar la siguiente afirmación: "El Centro de Estudios Humanísticos (CEH) duró mientras Torretti estuvo a su mando, pero en cuanto él volvió a Puerto Rico, en 1970, entró en una historia de decadencia que, creo, dura hasta ahora". Reitera lo mismo en la versión publicada en este número de la Revista. Es una afirmación gratuita. Roberto no necesita de este tipo de "reconocimiento": su gestión a la cabeza del CEH y la iniciativa misma de su creación, son cosa archisabida y reconocida. Por de pronto, él y Carla no partieron a Puerto Rico en 1970 sino en 1968. La diferencia no es trivial y no se cuenta en años: solo dos. Pero, los chilenos de cualquier lado del espectro político, saben muy bien que partir en 1970 significaba huir. Por otra parte, si el CEH, creado en 1963, hubiera declinado tan tempranamente, a los cinco años de edad, nadie se acordaría de él y no se justificarían estas líneas. Pero lo cierto es que su historia ha quedado asociada con la suerte de la Universidad de Chile desde fines de la década de los sesenta, de modo que la cronología de su muerte tampoco es indiferente en este caso. Además, el CEH adquirió cierta imagen pública, que la prensa se ha encargado de resaltar: El Mercurio le ha dedicado varias reseñas; The Clinic hace un recuerdo de la institución en el número dedicado a Parra, y en el libro de Tony Gould Death in Chile, dedicado a la memoria de su amigo Cristián Hunneeus, el autor le concede un buen espacio con entrevistas. Yo mismo, en un Seminario sobre la institucionalidad de la filosofía en Chile, presenté en la Universidad de Valparaíso una breve síntesis de su historia, que repaso aquí a grandes líneas.

Cuando comenzamos en 1963-64, quienes integrábamos el CEH, no pasábamos de cinco profesores de jornada completa. A pesar de que la Universidad de Chile entró en un período crítico en los años setenta, agudizado durante la intervención militar, el CEH continuó en expansión. Si hubo una repartición que se mantuvo indemne durante ese período de crisis institucional severa, e incluso creció, fue precisamente el CEH. Es fácil entender que una Facultad como la de Ciencias Físicas y Matemáticas gozara de ciertos fueros que no tuvieron otras; las ciencias sociales y las humanidades recibieron de lleno la represión desencadenada contra las universidades públicas. El $\mathrm{CEH}$ en este aspecto, fue un alero protector, algo así como la Academia original, creada justamente como refugio del pensamiento frente a los abusos del poder. En su período de mayor desarrollo, en los ochenta, el CEH llegó a contar con más de treinta investigadores de jornada completa, entre ellos, cuatro premios nacionales, un premio Príncipe de Asturias y un futuro Premio Cervantes y candidato al Nobel. Hacia fines de los setenta, el Centro se convirtió en Departamento y quedó habilitado para dictar sus propias Licenciaturas, independientes de las Ingenierías. Así nacieron las Licenciaturas en Filosofía, Historia y Literatura, donde se formaron los que hoy son profesores 
muy distinguidos: Pablo Oyarzún, Arturo Fontaine, entre muchos otros. Las nuevas Licenciaturas requirieron nuevas contrataciones y fue entonces cuando llegaron: Nicanor Parra y los historiadores Mario Góngora y Álvaro Jara, todos Premios Nacionales en sus disciplinas. A ellos cabe agregar: Enrique Lihn, Raúl Zurita, Jorge Guzmán, Cástor Narvarte, Genaro Godoy y muchísimos otros de excelencia equivalente. Todos ellos quedan gratuitamente ninguneados con la hipótesis de la temprana decadencia. La Biblioteca del Centro, convertido en Departamento (DEH) con la aprobación de las Licenciaturas, continuó también creciendo. A los generosos aportes institucionales, se sumó la biblioteca de Alejandro Lipschutz y la de Genaro Godoy, ambas donadas al $\mathrm{DEH}$, cuya Biblioteca llegó a ser una si no la más importante del país en ciertas áreas.

La investigación realizada en el DEH merecería mención aparte, pero para hacerse una idea, baste señalar que solía aprobar un número de proyectos equivalente o superior al de la Facultad de Filosofía y Humanidades completa. En fin, a mediados de los setenta se creó un sello editorial, que publicó más de cuarenta títulos, entre ellos inéditos de Parra, Lihn, Zurita, las memorias de Luis Oyarzún, la primera traducción al castellano de los escritos rectorales de Heidegger, comentada e interpretada; el primer libro sobre ética en la profesión de ingeniero publicado en Chile y uno de los pocos disponibles en castellano, entre muchos otros. Recién a mediados de los noventa vino la decadencia: se eliminaron las jornadas de investigación, se suprimieron las Licenciaturas, se liquidó la central de ediciones y se suspendió la adquisición de libros; todo eso en no más de dos o tres años y al cabo de una existencia de más de treinta. No hubo pues decadencia sino muerte súbita o más bien inmolación. Solo quedó el nombre de "Estudios Humanísticos", que paradójicamente sirvió de marca publicitaria a la hora de captar alumnos. Entiendo que hoy aún sobrevive como unidad de servicios docentes con profesores "taxis" o contratados por horas.

Me pregunto cuál es el propósito de lanzar opiniones tan antojadizas como la que comento, que faltan a la verdad y el respeto a personas ausentes. Si se pretendía hacer una impugnación a la Institución, mucho más punzante habría sido destacar su auge y prosperidad en medio de las penurias: eso ofende y puede entenderse. Pero ¿por qué destacar los méritos de unos a costa de agraviar a tantos otros? Es una gran paradoja, que un Centro creado en plena democracia sobreviviera y prosperara en Dictadura y sucumbiera en medio de la recuperación democrática, lo que indica cuan dañina puede ser la política de autofinanciamiento: el economicismo que la informa y su lógica de tendero, sin duda, cifraron la suerte de Estudios Humanísticos. 